\title{
Artículos
}

\section{La inmigración a la Argentina en los nuevos materiales digitales. ${ }^{1}$}

por Marisa Massone ${ }^{2}$ y Gisela Andrade $e^{3}$

Universidad de Buenos Aires

marisamassone@hotmail.com, giselafandrade@yahoo.com.ar

Recibido: 04/04/2016 - Aceptado: 29/04/2016

\section{Resumen}

Los materiales escolares constituyen una ayuda necesaria y difícilmente prescindible que median la práctica cotidiana de los docentes y la producción de los estudiantes en el quehacer cotidiano del aula. En los últimos años, la cultura material se viene transformando: si bien el uso de libros de texto sigue siendo predominante, éste se combinan cada vez más con la consulta de diversos sitios web, sugeridos por los profesores o hallados por los estudiantes. Partiendo de este presupuesto es que en este artículo analizamos una selección de materiales digitales para la enseñanza de los procesos migratorios en la Argentina. Reflexionamos sobre el lugar que ocupan los materiales multimediales para la enseñanza y las oportunidades que posibilitan para la reflexión sobre dichos procesos migratorios, analizando la perspectiva histórica que transmiten sobre el tema (temáticas, espacios, tiempos históricos y sujetos que privilegian), los lenguajes que utilizan, cómo interpelan la historia escolar y cuáles son sus posibilidades didácticas. En definitiva, este recorrido pretende ser de utilidad a la hora de definir criterios para la selección y evaluación de materiales disponibles en la web a ser usados en la formación inicial o continua, de los docentes en el área de Ciencias Sociales.

Palabras clave

enseñanza de la historia, formación docente, materiales digitales, historia escolar, inmigración

$$
* * *
$$

Immigration to Argentina in the new digital resources.

\section{Abstract}

School supplies are a necessary and hardly dispensable help that mediate in the daily practice of teachers and the production of students in the daily routine of the classroom. In recent years, the material culture has been transforming: while the use of textbooks is still predominant, it was combined with the consult of several websites suggested by teachers or found by students. From this point it is that in this article we analyze a selection of digital materials for teaching migration processes in Argentina. We consider the place of multimedia teaching materials and the opportunities that they allow for reflection on these migration processes, analyzing the historical perspective that broadcast on the topic (thematic spaces, historical times and subjects they privilege), the languages they use, how they interpellate school history and which are their educational possibilities. In short, this tour intends to be useful to define criteria for the selection and evaluation of materials available on the web to be used in the initial or further training of teachers in the area of Social Sciences.

\section{Keywords}

history teaching, teacher training, digital materials, school history, immigration

Clín \& Asociados. La historia enseñada. 20I6 (2Z) ISSN 2362-3063 (digital), pp. 20-40 Universidad Nacional del Litoral - Universidad Nacional de La Plata (Santa Fe/La Plata -Argentina) 


\section{Introducción}

"No es posible pensar el mundo educativo sin sus objetos (...) ya que la cultura material perfila el hacer activado en el interior de la escuela" (Finocchio, 2013). Enseñar la gran inmigración transatlántica de finales del siglo XIX y principios del XX en la Argentina ha sido un clásico en nuestras aulas. Ese proceso migratorio atado a la modernidad, la inserción de nuestro país en el mercado internacional como proveedor de materias primas, generó una mirada retrospectiva que acentuó diversos signos positivos en relación con las transformaciones sociales y culturales de la época. Pero la Argentina, como algunos otros países latinoamericanos como Brasil, entre otros, se caracteriza por ser receptores de mano de obra inmigrante en todas sus épocas. Europeos, latinoamericanos o asiáticos encontraron refugio en este país de fronteras abiertas, aunque no siempre con los mismos ojos ni acompañados con las mismas políticas. En las últimas décadas, particularmente a partir de la de 1990, el fenómeno de la inmigración limítrofe en Argentina viene generando un gran impacto en términos culturales y sociales, sobre todo en los grandes centros urbanos.

Orientar el análisis de aquel proceso histórico es una puerta de entrada esencial para pensar y analizar los procesos migratorios actuales, recuperando ideas y conceptos como las condiciones de expulsión y recepción, las redes sociales, las trayectorias personales, las relaciones familiares, las cuestiones de género y la niñez en el marco de los procesos migratorios, entre otros. Creemos ésta es una tarea ineludible de la formación docente y continua. Es por esto que nos proponemos analizar el lugar que ocupan los materiales digitales para la enseñanza y las oportunidades que éstos aportan para la reflexión sobre los procesos migratorios, analizando la perspectiva histórica que transmiten, las temáticas, espacios, tiempos históricos y sujetos que privilegian; los lenguajes que ponen en juego, cómo interpelan la historia escolar y cuáles son sus posibilidades didácticas.

Libros de texto, enciclopedias, láminas, revistas docentes, líneas de tiempo, carpetas, películas, historietas, videojuegos y materiales digitales son tecnologías, artefactos, objetos culturalmente producidos que acoplan lo material y lo simbólico (Vigotsky, 1979).Como en otras disciplinas escolares, también en la historia juegan un papel importante y son indisociables de las líneas del tiempo de lo social (Finocchio, 2013). Cambian en las diversas épocas, instalan representaciones sobre la educación y la sociedad y ensamblan saberes, prácticas y vínculos entre los sujetos que habitan la escuela. Esto es, no solo traducen la enseñanza de la historia sino que median la práctica cotidiana de los docentes y la producción de los estudiantes (Finocchio, 2011 y 2013).

Por estas razones consideramos que estudiar los materiales escolares tiene un sentido particular para nuestra tarea de formación docente inicial y continua. Reivindicamos su potencialidad como componentes sustantivos y presentes en la construcción de propuestas de enseñanza o secuencias didácticas, como soportes no neutros, que realizan una representación del mundo a enseñar, que condicionan y modulan la enseñanza, que seducen y emocionan a niños y jóvenes-estudiantes y a adultos-docentes, siendo clave el papel de éstos últimos "dándoles vida", seleccionando, usando, recomendando, recreando y produciendo nuevos materiales.

Del vasto universo de materiales que nutre las clases de Historia vamos a centrar la mirada en los materiales digitales. Se trata de webs de diversa naturaleza. Unas son meramente informativas, otras específicamente didácticas y algunas, una síntesis de ambos. Como los objetos propios de la cultura impresa, también muchas de los primeras devienen en las segundas, a partir del uso que de ellas hacen docentes y estudiantes (Johnsen, 1996). Son materiales cuya información está conectada hipertextualmente y/o tienen un formato multimedia, integrando 
textos, gráficos e imágenes fijas y en movimiento. Al mismo tiempo y para algunos casos, estos materiales permiten la comunicación entre sus usuarios o demandan la realización de actividades (Área Moreira, 2003).

Si bien las clases de historia continúan desarrollándose fundamentalmente a partir del uso de libros de texto o fragmentos fotocopiados de los mismos ${ }^{4}$, cada vez más se combinan con la consulta de diversos sitios Web sugeridos por los profesores o hallados por los estudiantes. Circulan materiales escolares digitales producidos en diferentes contextos y por diversas instituciones, como organismos públicos y/o empresas privadas. Al mismo tiempo, algunos profesores abren sitios en la Web con distintos propósitos que están disponibles para ser consultados y apropiados tanto por los alumnos como por otros profesores.

En este trabajo nos proponemos analizar el orden del saber histórico que se construye a partir de la posibilidad de combinar una diversidad de códigos propios de los materiales digitales, examinando la naturaleza, las cualidades historiográficas y pedagógicas, la cuestión de la autoría y el formato de una muestra de materiales digitales sobre la inmigración en la Argentina. Se trata de poner a disposición tanto de estudiantes como de docentes y formadores de formadores ciertos criterios para la selección y evaluación de materiales disponibles en la web que puedan ser usados en las aulas de Ciencias Sociales.

\section{Poner la mirada en los materiales digitales}

Estamos transitando un proceso de rápido cambio cultural producto del avanzado proceso de massmediatización: la significativa multiplicación de los medios masivos de comunicación y las nuevas tecnologías de la información que comenzó con el cine y la radio en el período de entreguerras, para desarrollarse en la década del cuarenta con la difusión de la televisión y consolidarse posteriormente con la invención de la televisión por cable, la satelital, la digital e Internet. En los últimos años, las industrias tradicionales del libro y el disco y los medios masivos de la comunicación ${ }^{5}$ como la prensa, la radio y la televisión se han adaptado y reconvertido a partir de la omnipresencia de la gran maquinaria de comunicación que es Internet, generando nuevas prácticas sociales y formas de mediatización. Las editoriales producen materiales multimedia e e-books. La descarga, almacenamiento e intercambio de canciones a través de Internet viene desplazando un consumo musical disco-céntrico. La radio también puede sintonizarse por Internet, en vivo interaccionando con lo grabado o a partir de la reproducción fonográfica de emisiones. La tecnología digital ha abaratado los costos de rodaje y postproducción de la industria cinematográfica, haciendo posible la circulación de cine aún por la Red y profundizando la desaparición del ritual de la sala a oscuras. La prensa diaria y periódica se sumergió en el mundo on line, como extensión de las publicaciones editadas previamente en papel u otras nuevas exclusivas del mundo digital. Asimismo se destacan las publicaciones on line del sector académico, un camino que abre una democratización en la distribución de conocimientos y amplía la divulgación científica. Las cadenas de televisión se han instalado en sitios web, adelantando o haciendo circular contenidos en la web. El pasaje de la televisión analógica a la televisión digital está aumentando la interactividad entre productores y espectadores. La tecnología digital también ha generado el desarrollo de videojuegos, tanto los que pueden jugarse a partir de la compra de un software como los que se brindan on line.

En este contexto de "ebullición cultural", las jóvenes generaciones cambiaron los modos de realizar tareas escolares, estudiar, informarse, divertirse, comunicarse, expresarse en diferentes disciplinas artísticas, mantener lazos de amistad o establecer estrategias de seducción, a partir de la naturalización y aceptación de las tecnologías de la comunicación y la información. También lo vienen haciendo los adultos, en mayor o menor medida. Cada vez más, las computadoras se

Clín \& Asociados. La historia enseñada. 20I6 (22) ISSN 2362-3063 (digital), pp. 20-4D. UNL - UNLP 
utilizan no solo para almacenar y bajar información sino también para enterarse de las últimas noticias, ver películas, series televisivas y videos, jugar, escuchar música y comunicarse con otras personas. Es que la convergencia digital, esto es, la integración de radio, televisión, música, noticias, libros, revistas e Internet implica no solo un nuevo proceso tecnológico, la aglutinación de múltiples funciones en una misma plataforma. Implica principalmente un cambio cultural, la reorganización de los modos de acceso a los bienes culturales y las formas de comunicación, generan hábitos culturales en lectores que a su vez son espectadores e internautas (Canclini, 2007, Jenkins, 2008).

En los últimos años, los desafíos generados a adultos-docentes y jóvenes- estudiantes se han profundizado a partir del avance de las políticas públicas nacionales y provinciales que invitaron a transformar las prácticas y objetos de lectura también en la historia escolar. En 2003, el Ministro de Educación Daniel Filmus durante la presidencia de Néstor Kirchner relanzó el portal de contenidos educativos Educ.ar creado dos años antes, constituyéndose en la principal propuesta de uso de Internet de la política educativa, asociada a la puesta en marcha de la Campaña Nacional de Alfabetización Digital. En 2004, el Ministerio de Educación, Ciencia y Tecnología creó el canal educativo Encuentro. Dos años después, la Ley de Educación Nacional nro. 26.206 impulsó con fuerza la inclusión de los componentes de la cultura contemporánea en el currículum oficial, desde el texto mismo de la ley (art. 11, inciso m; artículo 30, inciso f y disposiciones específicas, art. 88). En 2010, un programa de carácter universal que rompió con el modelo del laboratorio de informática y se propuso brindar la conectividad y el equipamiento tecnológico poniendo a disposición una netbook por alumno y por profesor/a (modelo 1 a 1), el Programa Conectar Igualdad, reunió una creciente producción. También generó la confluencia de contenidos educativos ya creados y otros nuevos potencializados con la creación de plataformas como Contenidos Digitales Abiertos (CDA) en 2013. Con dicho programa y el Plan Nacional de Inclusión Digital Educativa de 2015, enmarcado en el Plan Nacional de Educación Obligatoria y Formación Permanente (Res. Consejo Federal de Educación 188/12), sumados a algunos programas de jurisdicciones provinciales (como Plan Sarmiento en CABA o Primaria Digital del MEN) se buscó reducir las brechas digitales, educativas y sociales y revalorizar así la escuela pública. Esta política educativa inicialmente motorizada por el Plan Conectar Igualdad buscó acelerar el proceso de incorporación de las TIC en las aulas y llevó a estimular la producción y circulación de una diversidad de materiales multimediales que se venían elaborando desde diversos portales o canales educativos ${ }^{6}$.

Asimismo, esta política pública ha acelerado un proceso de metamorfosis también de los objetos portadores de conocimiento privilegiados de la cultura escolar, los libros de texto. La interacción texto-hipertexto o manual-red-multimedialidad viene cambiando las tramas textuales de los textos escolares de Historia (Escolano, 2006): una composición propia del hipertexto aún en la materialidad del soporte papel; un componente multimedial a partir del empleo de diversos lenguajes además del tradicional lenguaje textual; diversas propuestas de búsquedas, lecturas y escrituras en Internet y secciones específicas del libro vinculadas con el uso de TIC. Es así que una nueva generación de textos escolares metamorfoseados en pantallas vienen acompañando el camino para leer en pantallas (Massone, 2012) a partir del ofrecimiento de una diversidad de materiales digitales. De muy diversos modos los libros de texto de los últimos años se abren a otras lecturas, más allá del soporte papel: fuentes escritas en manuales digitales o en Internet; $e$ books; diarios digitales; fotografías, dibujos, caricaturas, pinturas y galerías fotográficas y pictóricas en diversos sitios web; entradas de enciclopedias digitales y colaborativas como Wikipedia; audios o transcripciones de testimonios orales; programas de radio y televisión; películas de ficción y documentales (o sus fragmentos en la plataforma para el intercambio de materiales audiovisuales creada en 2005, YouTube); dibujos animados; microvideos 
(documentales de un minuto de duración); docuficciones (híbridos entre la veracidad de la tradición documental y la libertad narrativa de las ficciones); historietas en soporte virtual y animadas; infografías digitales y animadas; mapas históricos virtuales y animados, consultados o construidos en google earth; guiones de museos virtuales; literatura; letras y videos musicales y restos del patrimonio arquitectónico en soporte digital, producidos en mayor medida por organismos públicos y en menor, por iniciativas privadas (de las editoriales o de colectivos docentes, por ejemplo) para utilizarlos on line, off line y en red.

Por lo tanto no podemos seguir pensando en una historia escolar transmitida solo por los libros (Chartier, 2009) porque la gran conversión digital, una mudanza de enorme magnitud tal que "impregna, e incluso define, una nueva vida cotidiana" (Doueihi, 2010:88) ya ha alcanzado a la Historia como disciplina escolar (Massone, 2013). Resulta entonces un desafío el estudio de una diversidad de materiales digitales, potencialmente presentes en las aulas de historia, a través del desarrollo de las clases o las tareas escolares.

Los estudios sobre materiales digitales asociados a la historia como disciplina escolar, como páginas web o juegos digitales, aún resultan escasos. En Brasil, E. Pimenta Arruda y L. Mara de Castro Simian (2009) estudian las relaciones entre las estrategias de aprendizaje utilizadas por los jóvenes que usan juegos digitales con contenido histórico y las estrategias de enseñanza y aprendizaje puestas en juego por los profesores en el ambiente escolar. En otro trabajo, E. Pimenta Arruda (2011) analiza las narrativas y la reconstrucción histórica que desarrollan estos mismos juegos. Al mismo tiempo, existen otros trabajos que estudian el saber historiográfico en relación con los nuevos materiales educativos. Por un lado, Adriana Carvalho Koyama (2013) desarrolló una investigación sobre los sitios web de memoria. Por otro, Maio Fonseca y Silva Alves (2012) examinan la concepción y los contenidos de la historia adoptados por los sitios más consultados por los jóvenes estudiantes para realizar sus tareas escolares.

En Uruguay y Argentina, el desarrollo de investigaciones referidas a esta temática son aún menores. Entre las existentes, son más numerosas las que indagan la integración de las TIC al curriculum de Historia desde una lógica aplicacionista, instrumental, es decir, analizando la introducción de diversos dispositivos tecnológicos en las clases de historia eludiendo la reflexión sobre la naturaleza del saber que se transmite a través de los mismos. Así lo plantean Andino y otros (2012) para el caso uruguayo, en relación con el Plan Ceibal. Por otra parte, en Argentina, A. Segal (2012) estudia el uso de videojuegos para tratar temas de la agenda contemporánea de las Ciencias Sociales, con materiales de desarrollo propio de su equipo de investigación. También V. Cuesta y E. Marchese (2013) analizan los usos posibles y las potencialidades de una breve selección de materiales vinculados con la historia reciente del portal Educ.ar, entre otros, examinando tanto el tratamiento disciplinar como didáctico de los temas tratados.

A partir de este breve panorama, creemos que resulta un desafío profundizar investigaciones que examinen los diferentes materiales digitales existentes y posibles de ser trabajados en las escuelas como un modo de interrogar los rumbos y sentidos de la enseñanza de la historia hoy.

\section{La inmigración en la Argentina}

\section{2. a. Una síntesis de la historia de la inmigración}

Del mismo modo que los libros de texto u otros materiales, los materiales digitales median en el proceso de adquisición de conocimiento, esto es, son agentes de los procesos de reconfiguración de los saberes escolares. Es por esta razón que para su análisis hemos elegido el desarrollo de un saber escolar en particular, la inmigración en la Argentina.

¿Por qué estudiar este tema? En primer lugar, porque estamos hoy atravesando una nueva realidad social que habilita a hombres, mujeres y niños con diversas experiencias migratorias a

Clío \& Asociados. La historia enseñada. 20I6 (22) ISSN 2362-3063 (digital), pp. 20-4D. UNL - UNLP 
incorporarse a nuestras aulas como estudiantes y como docentes y nos enfrenta a un nuevo desafío. En segundo lugar, porque se trata de una temática de amplia y reconocida producción académica desde la Sociología, la Geografía, la Antropología y la Historia en nuestro país y con una gran presencia en las Ciencias Sociales y la Historia como disciplinas escolares. En tercer lugar, porque incorpora la producción de una amplia agenda política que busca responder no sin limitaciones a ella ${ }^{7}$ Por último, porque incorpora una agenda mediática que encuentra a los sujetos migrantes a veces como víctimas de la opresión al mismo tiempo que como amenaza económica y social en la Argentina. Es así que encontramos a las transformaciones sociales, políticas, económicas y culturales relacionadas con los procesos migratorios como un núcleo temático interesante para revisar las cuestiones socialmente vivas en la actualidad, de nuestro país, la región y el mundo (Falaize, 2011, Finocchio, 2015). Estos sentidos nos llevan a recuperar los aportes de los análisis historiográficos actuales tanto del proceso histórico de fines de siglo XIX y principios del XX como de los procesos migratorios recientes, a partir de ideas y conceptos como las condiciones de expulsión y recepción, las redes sociales, las trayectorias personales, las relaciones familiares, las de género y la niñez en el marco de los procesos migratorios, entre otros.

Enseñar la gran inmigración transatlántica de finales del siglo XIX y principios del XX en la Argentina ha sido un tema clásico en nuestras aulas, haciéndose eco en un primer momento de los análisis que veían a este proceso migratorio atado a la modernidad, a la inserción de nuestro país en el mercado internacional como proveedor de materias primas. Esa vinculación con la expansión económica hizo que la mirada retrospectiva de tal proceso vea con signos positivos las transformaciones sociales y culturales que éste había generado. Así, esta migración masiva transatlántica fue leída desde una perspectiva integracionista por académicos como G. Germani o J. L. Romero, entendida como un proceso en el cual los inmigrantes se habían asimilado con bajo grado de conflictividad en la sociedad preexistente. De esta forma, el impacto de la misma se traducía en la clásica imagen de un crisol de razas construido por elementos muy diversos, italianos, españoles, franceses, polacos, sirios, libaneses, entre otros, que por efecto de un factor externo como es el calor en la fundición, perdieron sus diferencias originales dando origen a una nueva sociedad. Esta perspectiva historiográfica estuvo íntimamente asociada a la experiencia social inmigratoria que vinculaba la idea de la Argentina como granero del mundo al reconocimiento del valor del aporte de la mano de obra inmigrante en su construcción ${ }^{8}$. Este relato se refuerza, por ejemplo, subrayando el mensaje del preámbulo de la Constitución Nacional que en todas sus reformas ha sostenido que la Nación argentina, un país de fronteras abiertas, está destinada "...para todos los hombres del mundo que quieran habitar en el suelo argentino..." dando lugar a europeos, latinoamericanos o asiáticos, aunque no siempre mirados con los mismos ojos ni sostenidos por las mismas políticas. Más tarde, el desarrollo historiográfico sobre los estudios migratorios en la Argentina de las últimas décadas del siglo XX y primeras del XXI vino a cuestionar estas ideas, basándose en el presupuesto de que tanto los inmigrantes como nativos aportaron a la construcción de una nueva identidad. Así, una importante cantidad de trabajos buscaron hacer visibles las diferencias desde una idea de pluralismo que se proponía mostrar cómo, en ese proceso migratorio, coexistieron diversas identidades. De este modo, los trabajos de F. Devoto en una primera instancia o los de M. Bjerg, entre muchos autores, criticaron las perspectivas tradicionales e introdujeron conceptos claves como el de cadenas migratorias en el inicio y redes sociales, posteriormente. Mientras el primero permitió visibilizar el movimiento de la población e identificar cómo los vínculos interpersonales fueron una de las principales motivaciones de atracción de la población más allá de los factores macro sociales; el segundo, complementando y ampliando lo anterior, ha permitido ver a los inmigrantes como actores racionales que perseguían objetivos y para ello movilizaron los medios que tienen disponibles, 
recursos relacionales necesarios e útiles para conseguir información, elegir destino o insertarse en el mercado de trabajo de la sociedad receptora (Ramella, 1995). Los trabajos de estos autores también permitieron, a través de diversos estudios de caso, visibilizar los conflictos, el pluralismo cultural y las representaciones e identidades construidas por los distintos grupos étnicos y la sociedad receptora.

Desde estas perspectivas historiográficas se ha analizado el proceso migratorio en la Argentina iniciado hacia fines del siglo XIX, cuando arribaron gran cantidad de inmigrantes europeos (italianos, españoles y en menor medida, rusos, judíos, franceses, polacos, alemanes, suizos, entre otros). Su arribo masivo alteró la composición de la población del país. En 1895 llegaron a constituir el $25 \%$ de la población total y en 1914, el 30\%, generando una fuerte incidencia en la estructura demográfica y también en la económica y social de la Argentina que opacó por completo la presencia histórica y permanente de migrantes de los países limítrofes, existente ya en la época colonial (Pacceca y Averbuj, 2014). La mayor parte de esa población inmigrante estaba compuesta por hombres y en menor medida por mujeres, ambos en edad activa que constituyeron una importante oferta de mano de obra, no calificada y vinculada al trabajo rural. En general, se declaraban agricultores o jornaleros. Algunos pocos manifestaban poseer calificación profesional específica, como carpinteros, herreros, costureras, tejedores o imprenteros (Devoto, 1992).

Los flujos y reflujos migratorios que se dan en la Argentina desde mediados de siglo XIX permiten identificar los múltiples factores que definieron la expulsión y la recepción de este gran número de población. Según el lugar de origen de los inmigrantes, se combinaron situaciones nacionales, locales, familiares y personales que explican su movimiento migrante. Dentro del conjunto de causas de tipo económicas prevalecieron las vinculadas a la crisis de las zonas rurales europeas. La creación de nuevos mercados, los cambios en los precios de los productos sumados a las innovaciones tecnológicas, expulsaron gran cantidad de campesinos y minifundistas. A las causas económicas se agregaron causas de tipo demográficas. Hacia fines del siglo XIX Europa sufrió un importante crecimiento vegetativo de la población. Pero la población no creció al mismo tiempo que el trabajo y los recursos económicos. Por esta razón, quienes no encontraban sustento en su país, se vieron forzados a migrar. Más avanzado el siglo XX, otros grupos étnicos, se vieron obligados a emigrar por persecuciones políticas o religiosas. Entre ellos se destacaron los armenios, entre 1910 y 1920, y los judíos en la década de 1930. En estos casos, la emigración no era una alternativa posible entre muchas otras sino un modo de supervivencia.

También son varias las razones que explican por qué los migrantes eligieron la Argentina para establecerse. La expansión agropecuaria de nuestro país a partir de 1850 creó posibilidades laborales tanto en el campo como en la ciudad. Además, como hasta fines de siglo XIX la demanda de trabajadores era mayor que la oferta, los salarios aumentaban (aunque con alteraciones estacionales). Esto convertía a la Argentina en un país suficientemente atractivo como para competir con la inmigración masiva de países como EEUU o Canadá.

Al mismo tiempo, el proceso de formación del Estado argentino encontró en la incorporación de mano de obra europea una posibilidad para la consolidación de su posición como país exportador de materias primas. Esto no solo lo definió en su Constitución Nacional, como lo señalamos anteriormente, sino en una serie de políticas como la Ley de Inmigración y Colonización $\left(\mathrm{N}^{\circ}\right.$ 817) de 1876 que promovió la organizaron de diversas colonias rurales, a menudo con subvención estatal, para ocupar regiones claves de los territorios nacionales. Además, fomentó la inmigración con pasajes subsidiados, alojamiento en el Hotel de Inmigrantes a los recién llegados y pasajes gratis para trasladarse al interior del país.

El país les ofrecía un marco legal que promovía las libertades y derechos vigentes en la Constitución y en la legislación positiva. A la vez definió un marco legal que apuntó al control y

Clío \& Asociados. La historia enseñada. 2016 (2Z) ISSN 2362-3063 (digital), pp. 20-40. UNL - UNLP 
represión de aquella población inmigrante cuando el conflicto social se hizo presente, a través de la Ley de Residencia ( $\mathrm{N}^{\circ}$ 4144) de 1902 y la Ley de Defensa Social ( $\mathrm{N}^{\circ}$ 7029), desplegando estrategias que buscaron encausar la inmigración sin dejar de lado esa política de puertas abiertas sostenida por la Constitución (Bjerg, 2009). La educación libre y gratuita sirvió entonces como una posibilidad de ascenso social así como un factor de disciplinamiento y argentinización de los hijos de estos inmigrantes. Aun en momentos complejos de crisis política e imposición de un régimen autoritario como el impuesto durante la última dictadura cívico militar en Argentina, el gobierno mantuvo la idea de la promoción de la inmigración más allá de las limitaciones y condicionamientos que a ésta le impone a través del Decreto-Ley de Migraciones y de Fomento de la Inmigración (Ley N ${ }^{\circ} 22.439$ ) conocida como ley Videla de 1981.

En las últimas décadas, particularmente desde 1990, el fenómeno de la inmigración limítrofe en Argentina viene generando un gran impacto en términos culturales y sociales, sobre todo en los grandes centros urbanos. No se trata de una nueva inmigración, ya que las estadísticas censales confirman que desde el primer censo en 1869 hasta el de 2001, los migrantes de países limítrofes, incluyendo Perú, se sostuvieron en un porcentaje de entre el $2 \%$ y el $3 \%$. Sucede, por un lado, que mientras hasta esa década los inmigrantes limítrofes estaban asentados en zonas de frontera, a partir de entonces, con la crisis de las economías regionales, comenzaron a desplazarse hacia los grandes centros urbanos. Por otro, cambió la distribución de las nacionalidades de la totalidad de los inmigrantes limítrofes, aumentando el número de paraguayos, bolivianos y peruanos en detrimento de chilenos y uruguayos. A su vez, estos inmigrantes -ahora visibles en las ciudades- reclamaban su legalización y documentación al tiempo que difundían su cultura para revertir la valorización negativa sobre sus identidades, en medio de una política oficial sistemáticamente xenófoba y un profundo proceso de estigmatización social de hombres y mujeres migrantes latinoamericanos. Así es como ha cambiado el régimen de visibilidad de la etnicidad en la Argentina. Esto es, se pasó de una situación de invisibilización de la diversidad a una hipervisibilización de las diferencias (Grimson, 2005 y 2015). Estas transformaciones golpearon un imaginario fuertemente instalado en la Argentina resumida en la frase "los mexicanos (o los peruanos, o los bolivianos) descienden de los indios y los argentinos descienden de los barcos". Es decir que mientras tanto México como Perú sostienen un imaginario nacional creado sobre la base del mestizaje, la Argentina imagina uno basado en la inmigración europea, desatendiendo su realidad demográfica, política y económica. Dicho imaginario estalló con la crisis económica de 2001, y luego generó contradicciones y conflictos sociales con la implementación de políticas públicas ${ }^{10}$ enmarcadas en Ley Nacional de Migraciones $\mathrm{N}^{\circ} 25.871$ de 2003 que reconoce, amplía y garantiza los derechos de los inmigrantes, incluso para aquellos sin documentación.

Es así que esta tradición y vigencia de la Argentina como país receptor de población inmigrante instala el compromiso de pensar y revisar los nuevos sentidos que adquiere la enseñanza de los procesos migratorios en nuestras aulas.

\section{2. b. El tratamiento de la inmigración en la historia escolar}

Las escuelas se han construido a partir de una imagen de la Argentina como un país históricamente receptor de migrantes europeos considerado crisol de razas, una amalgama entre la población nativa e inmigrante, fundida en armoniosa convivencia, que aún perdura. Así, transmitieron un relato melancólico y cuasi folklórico de la integración. Esta imagen etnocéntrica sostuvo una contracara sostenida de componentes racistas o xenófobos hacia los migrantes internos y externos, provenientes del Interior los primeros y de países limítrofes y Perú, los segundos. Una mirada, sedimentada en los sentidos cotidianos de familias y docentes de las 
escuelas, entre otros sujetos, y que ha aportado a la co-construcción de la tipificación de las escuelas producto de una evaluación social y una rotulación de estas instituciones. Así, la concentración de población migrante "funcionaba como estigmatizante respecto de las escuelas a las que asistían, mancha que también recaía sobre los docentes y los alumnos de las mismas" profundizando así los procesos de fragmentación social y territorial (Neufeld, 2013:12).

Al mismo tiempo, en su tratamiento curricular, las temáticas vinculadas con la inmigración han ganado algunos espacios en las propuestas curriculares y los materiales de desarrollo curricular de las distintas jurisdicciones del país, ya desde la primera década del siglo XXI. En una primera aproximación a los diseños curriculares de la Ciudad de Buenos Aires, de la Provincia de Buenos Aires y los lineamientos que definen a escala nacional los Núcleos de Aprendizaje Prioritarios ${ }^{11}$ podemos inferir que las temáticas sobre inmigración se van haciendo presentes, no sincrónicamente en los distintos niveles y regiones del sistema educativo. Se ha avanzado mucho en la formulación de la problemática de la inmigración ultramarina como un eje determinante en la formación de la Argentina Moderna y su inserción en el mercado internacional, proponiendo profundizar los aspectos de la vida cotidiana de esos hombres $\mathrm{y}$ mujeres, una temática que se reitera en todos los niveles de la escuela -primaria, secundaria y formación docente-. En menor medida se referencia a los procesos de migraciones internas. Una presencia aún menor tienen las definiciones curriculares o las propuestas que interpelen a los docentes a abordar los problemas relacionados con las migraciones actuales en nuestro país.

Existen unos pocos trabajos que analizan el tratamiento del tema de la inmigración en la Argentina, centrada especialmente en libros de texto de diversos contextos y niveles educativos.

R. Cucuzza (2009) analiza los libros de lectura de escuela primaria producidos entre 1873 y 1930. En general prevalece en los textos consultados esa amplia convocatoria sellada en el preámbulo de la Constitución del 53 acerca de los "hombres de buena voluntad que quieran habitar el suelo argentino" evitando las referencias al clima de agitación social generado por las huelgas o los atentados anarquistas, el origen del movimiento obrero, las transformaciones del discurso de la elite dirigente en relación con los inmigrantes o sus respuestas represivas como la Ley de Residencia.

Fernando Devoto (1992) estudia el lugar que ocupa el tema de la inmigración en los primeros libros de texto entre 1912 y 1974. Concluye que además de ocupar un escasísimo espacio, desproporcionado en relación con otros temas, la cuestión social casi no aparece así como tampoco las condiciones de vida de la población o solo se hacen breves referencias a hechos violentos atribuidos a agitadores profesionales, no siempre descriptos como extranjeros. Además, el proceso migratorio se detalla como un tema asociado a las acciones de gobierno de los diversos presidentes y en particular, a los proyectos colonizadores de Urquiza, sugiriendo así que los inmigrantes se habían dirigido solo a las zonas rurales. En ocasiones, la inmigración transatlántica también es presentada como parte del proceso de incorporación al mercado mundial, ligada al tratamiento de la formación de la Argentina moderna. Así, el proceso de la inmigración masiva europea se presenta como clave para el tránsito de la barbarie a la civilización, y asociada a la idea de "crisol de razas" considerada constitutiva de una identidad nacional de mezcla, integración y mejora racial, social y cultural.

María Paula González (2004) examina una muestra de libros de texto producidos luego de la Ley Federal de Educación (1993). Allí se promueve la complejización del tema a partir de la incorporación del análisis de condiciones de vida y los conflictos sociales. A pesar de ello, se observa un tratamiento "autosuficiente" de la inmigración masiva europea, sin conectarla con otros procesos migratorios posteriores o actuales de la Argentina (González, 2004). Tal como plantea la misma autora y recuperando los estudios sobre textos escolares dirigidos por L. A. Romero (2004) esta mirada está asociada a la imagen construida de la Argentina como "un país

Clía \& Asociados. La historia enseñada. 20I6 (2Z) ISSN 2362-3063 (digital), pp. 20-4D. UNL - UNLP 
predominantemente blanco, y en todo caso, el más blanco de América Latina" (Romero, 2004:203). Como se señaló anteriormente, se trata de una idea edificada más allá de cualquier evidencia empírica que ha consolidado la visión de una identidad nacional ya construida y acabada.

De modo más reciente y avanzando sobre un tema poco explorado María Soledad Balsas (2014) analiza el rol de la mujer en las migraciones internacionales a partir de una amplia muestra de libros de texto para la escuela primaria publicados en los últimos años. Para la autora, en general esta migración es tematizada vinculada a una estrategia asociativa en la que los protagonistas de los movimientos migratorios son los hombres. Asimismo, las tareas femeninas casi siempre aparecen ligadas al trabajo doméstico o a tareas poco calificadas o próximas al mismo. Sus conclusiones robustecen y confirman las hipótesis compartidas por otros autores:

Parafraseanda a Wainerman (20D3), los libros escalares argentinos repiten ad nauseam una perenne división sexual del trabaja migrante que adquiere matices diversos según el país de proveniencia.

Dentra de un discursa hegemónica que valora las migraciones en términas de aparte demagráfica, destaca la visión instrumental del supuesta ral biológica de las eurupeas. Sabre esta base, se postula el arigen eurapea de la argentinidad. Las migraciones protagonizadas por mujeres latinaamericanas, en cambia, san más proclives a ser representadas en términos independientes en el marca de la tearía de los mercados de trabaja segmentados. La abservada se torna particularmente evidente a partir de los textas visuales. Las migrantes asiáticas y africanas están comparativamente menos visibilizadas. (Balsas, 2014:s/d)

\section{2. c. Algunas evidencias en los materiales digitales}

Nos hemos propuesto recoger evidencias empíricas que permitan problematizar los sentidos pedagógicos e historiográficos que establecen sitios Web orientados a la enseñanza de la historia o que presentan propuestas que se apropian con ese fin, en este caso, de la inmigración en la Argentina. Nos ha interesado indagar en los formatos, las autorías y los significados tanto pedagógicos como historiográficos de estos materiales educativos digitales con el objeto de conocer las disputas sobre el pasado y los sentidos educativos presentes en sitios que suelen tener una apariencia fluida y transparente para muchos de sus usuarios. Así, como señalamos más arriba, hemos analizado la perspectiva histórica que transmiten, las corrientes historiográficas presentes, las áreas temáticas privilegiadas, las dimensiones de la realidad social ponderadas, los sujetos históricos incluidos, los espacios geográficos comprendidos y el tratamiento del tiempo histórico abordado. También hemos estudiado en qué medida cada uno de los materiales interpela la historia escolar, si propone la apertura hacia otros materiales y a quién se dirige su uso. La cuestión de la autoría de los materiales se indagó considerando las licencias bajo las cuales circulan, los modos en que dan cuenta del proceso de construcción del conocimiento y las características de los sitios donde se alojan. Por último, hemos analizado el formato de los materiales digitalesconsiderando elsentido estético de los sitios, las sensibilidades que éstos promueven, los protocolos de lectura y escritura establecidos y las posibles interacciones con los usuarios.

Al mismo tiempo, hemos utilizado diversos criterios para la selección de la muestra de sitios examinados. Esto es, sitios web producidos en la Argentina con propósitos educativos; materiales digitales diseñados para la enseñanza de la historia cuyo destinatario principal son los profesores de historia; sitios con diversas autorías y por último, otros producidos y financiados por distintas instituciones / individuos / colectivos. La exploración de estos objetos on line se procesó a través de fichas descriptivas que han permitido relevar y sistematizar tanto las evidencias vinculadas con los diferentes formatos y con la autoría como con los ordenamientos discursivos, a partir de palabras claves o signos iconográficos. La sistematización y el análisis de la información 
recolectada apuntarán a la identificación tanto de lo singular como de los elementos comunes de cada sitio, desde una perspectiva comparada. Veamos a través de algunos ejemplos el tratamiento que los materiales digitales le dan al tema de la inmigración en la Argentina.

En primer lugar, hemos analizado dos materiales asociados a la producción personal de historiadores con trayectorias diversas, uno vinculado a la divulgación de masas con fuerte presencia mediática y otro, inserto en la producción académica y con un recorrido vinculado al desarrollo de la divulgación histórica.

El sitio más visitado de la Argentina", el de "El Historiador" dirigido por el historiador de masas Felipe Pigna http://www.elhistoriador.com.ar/ se presenta como interpelando la historia escolar a partir de un supuesto nuevo relato que viene a saldar las verdades y omisiones excluidas de la narrativa "oficial". Si bien incluye secciones como "Multimedia" que contiene cronologías multimedia, infografías temáticas y programas de TV, "Historia para ver" con tiras de humor y publicidad históricas y una "Historia para escuchar" con audios y programas de radio, en general, en el acceso a los temas predominan la lógica del hecho singular y de la efeméride. Es así también en la sección "Archivo" que presenta síntesis históricas, documentos, artículos, biografías, entrevistas, datos y estadísticas, frases y anécdotas, efemérides y una sección de historia en el aula. Desde esta lógica, el tema de la inmigración aparece fragmentado en diversos textos organizados dentro de la llamada "gaceta histórica" a las cuales se accede mediante un buscador interno. Se alude a la inmigración a partir de la obra de distintos presidentes, como Sarmiento, Avellaneda o Roca. En relación con el segundo, se refiere a la legislación, la Ley de Inmigración y Colonización 817, llamada Ley Avellaneda. En otra gaceta titulada "Los hombres de buena voluntad" se propone contar la historia no contada señalando que el fenómeno inmigratorio es anterior a 1880 (vascos e irlandeses / genoveses) y que los migrantes de esa época tenían carácter de golondrina para culminar analizando el censo de 1869, a partir de un relato construido en base a textos y estadísticas. Por último, en este sitio, la autoría de los textos no se explicita aunque se deduce las producciones pertenecen al director del mismo, quien cuenta con un importante staff de colaboradores. Las citas existentes referencian básicamente fuentes primarias, por ejemplo, entre otras, los censos nacionales. La historia aquí transmitida reproduce lo más tradicional de la historia escolar, una historia de la inmigración asociada a las presidencias históricas.

Otro sitio de un historiador, con un alcance muy distinto al anterior, es el blog de Ezequiel Adamovsky "Historia y antagonismo" http://ezequieladamovsky.blogspot.com.ar/ que también reúne textos de su autoría, intervenciones en los medios masivos de comunicación y trabajos realizados en el marco del seminario "La divulgación histórica: Reflexiones y prácticas desde el oficio del historiador" dictado en 2013, entre otras producciones. Allí se presenta el trabajo de por entonces dos estudiantes, Milena Ortuondo y Belén Lo Russo, un video en estilo "Drawmylife" sobre la historia de la inmigración en Argentina con otro blog que lo acompaña y complementa, un blog que invita al comentario de los lectores (no hay escrituras) y cuenta con 24888 visitas totales http://inmigranteshistoriasdefamilia.blogspot.com.ar/ En un lenguaje sencillo se genera un relato complejo de la historia de la inmigración abordando una periodización que va de 1880 a 1914. Se define la "ola inmigratoria" o "era aluvional", se alude a los factores de expulsión a partir de un caso familiar y nacional (España), a las políticas públicas de atracción de inmigrantes como el Hotel de Inmigrantes, a las condiciones de vida y de trabajo de los inmigrantes, la cuestión social, las políticas represivas del Estado y a la participación política de los inmigrantes. Asimismo, incluye una historia cultural de la inmigración, se presentan como parte de la misma temática, los espacios de sociabilidad, los matrimonios endogámicos y la discriminación. Resulta interesante cómo dicho material recupera en su relato a actores sociales colectivos como el Estado Argentino y los inmigrantes, subrayando diferencias

Clío \& Asociados. La historia enseñada. 20I6 (2Z) ISSN 2362-3063 (digital), pp. 20-40. UNL - UNLP 
nacionales e ideológicas y cierta multiperspectividad sobre el tema: el ascenso social de los inmigrantes versus la expulsión de los mismos por participar de las luchas obreras. Utiliza tiempos simultáneos -lo que sucede en Europa y en Argentina- ampliando la idea de flujo migratorio con explicaciones varias como las transformaciones de la tasa de radicación. Pone en juego un lenguaje visual y sonoro que además ensambla (hace link) con fotografías de época. Resulta valiosa cómo esta pequeña producción interpela la identidad nacional construida a partir de la idea "los argentinos descendemos de los barcos" presente en el discurso escolar y social. A lo largo de su desarrollo, las autoras rebaten dicho presupuesto presentando a la Argentina como un espacio de diversidad cultural, apelando a la preexistencia de los indígenas aunque omiten la inclusión de los afrodescendientes.

Asimismo, hemos analizado un grupo de materiales digitales producidos por el Ministerio de Educación de la Nación en las últimas gestiones, desde el portal Educ.ar, el Canal Encuentro y el Programa Conectar Igualdad. En un amplio conjunto, hemos seleccionado dos producciones: Valencia (http://historiavalencia.educ.ar/) y [Re]Pensar la Inmigración en Argentina (http://valijainmigracion.educ.ar/), ambos presentados como minisitios ${ }^{13}$ de Educ.ar.

Valencia -historieta interactiva- es una historieta digital desarrollada en ocho capítulos y producida en 2010. Cuenta la historia de una familia, los Valencia, como una excusa para recorrer los últimos 100 años de la historia argentina, del Centenario al Bicentenario, temporalidad que organiza sus capítulos. Cada uno de los capítulos puede descargarse independientemente y a su vez, la propuesta de lectura de sus viñetas es sucesiva. Los textos de la historieta incorporan sonidos y voces, ingredientes optativos para su navegación. Acompaña su presentación con propuestas para el aula y se puede navegar on line o descargar en PDF. Una historia de familia comienza a contarse a partir de la inmigración transatlántica. El primer episodio recupera la historia de vida del abuelo del protagonista al llegar a la Argentina, un hombre de origen español cruzado por los grandes sucesos políticos y sociales de la Argentina, como la Semana Trágica. Así, esta historia familiar da cuenta del impacto de la dimensión política y social en la vida cotidiana de una familia y de un país, tal como lo hace el video de Milena Ortuondo y Belén Lo Russo analizado anteriormente. Si bien no centra el relato en los procesos migratorios sí los recupera como parte fundante de la Argentina moderna.

Es un material desarrollado con fines didácticos, para ser usado y disfrutado por docentes y alumnos. Entre sus créditos figuran especialistas dedicados a la producción tanto del guión como del dibujo y animación. La investigación histórica fue realizada por Julia Rosemberg con el asesoramiento de Javier Trímboli. Daniel Finquelievich y María Victoria Scarsison son los responsables de las propuestas de actividades para el aula.Busca recuperar la narración e invita al docente a complejizar el conocimiento histórico desde el relato de la vida cotidiana de los distintos actores sociales. Desarrolla nudos problemáticos de acuerdo a los lineamientos curriculares y las perspectivas históricas hoy validadas por el ámbito académico, incorporando temas y problemas relativamente nuevos para la historia escolar, temas que vienen pujando entrar a las aulas desde la recuperación democrática, como la historia del movimiento obrero, el impacto de la Guerra Civil Española en la Argentina, la lucha armada y la violación a los derechos humanos a lo largo del siglo XX. Sin embargo, en relación con la temática de la inmigración en la Argentina genera más continuidades que rupturas o interpelaciones a la historia escolar tradicional ya que, en algún lugar está firme y presente o se refuerza la idea de que los "argentinos bajamos de los barcos", sobre todo si no se hacen referencias a otros procesos migratorios posteriores. En el mismo sentido, como parte de la crisis del 2001 aparece la idea de la emigración, sin hacer referencia a ningún otro proceso migratorio a lo largo del siglo XX, más allá de la inmigración ultramarina. 
El minisitio "[Re] Pensar la Inmigración en Argentina", a diferencia de "Valencia" y de los sitios de Pigna y Adamovsky, es un material centrado en una perspectiva antropológica e interdisplinaria. Destaca diversos aspectos de la realidad social argentina vinculados con los procesos migratorios. Presenta la problemática sin circunscribirla temporalmente, sin embargo, sus propuestas están centralmente pensadas con el objeto de revisar los procesos actuales. Realizado por el Ministerio de Educación de la Nación conjuntamente con la Universidad Nacional de Lanús, Unicef y Cine Migrante, este material disponible en la web fue coordinado por Ana Paula Penchaszadeh y María Inés Pacecca y contó con el trabajo de un amplio equipo ocupado tanto de la selección y búsqueda de materiales como de la producción de textos propios y desarrollo de propuestas para el aula. En su navegación podemos encontrar dichos materiales, bibliografía sugerida, links de cortos disponibles en YouTube de altísima calidad con sus respectivas referencias. Se trata de un micrositio con navegación cerrada que también tiene una versión off line en formato CD distribuida en las escuelas. Su navegación interna no es lineal. Se explora sin un orden determinado y su organización interna permite un ir y venir en la bibliografía y los materiales. La imagen es muy poco explotada. Prácticamente sus textos no tienen imágenes, solo cuadros muy gráficos y explicativos de las temáticas desarrolladas y una invitación a consultar videos en YouTube o Vimeo. Resulta un valioso material para la formación docente que incluye un texto marco sobre las razones para pensar la inmigración; otro sobre el marco pedagógico, bibliografía, materiales de consulta y ampliaciones en formato PDF y propuestas para trabajar en el aula para los niveles primario y secundario interpelando la historia escolar al introducir el tema de la inmigración actual en la Argentina. Su organización, sin embargo, obtura un poco la navegación. La propuesta invita a la exploración de material audiovisual, sin direccionarlos desde la navegación, solo se los referencia y acompaña con materiales propios para la profundización en la temática y propuestas concretas para el aula. Los destinatarios son docentes a quienes se invita a recuperar en sus aulas los procesos migratorios actuales, descriptos y desarrollados teóricamente en este micrositio. Tanto en sus textos disciplinares como en las sugerencias de tratamiento didáctico se refuerza la apuesta manifestada en su presentación:

Recarrer estas imágenes y cuntextualizarlas en relación a la dinámica de los flujos migratorios y la normativa pasada y presente nos permitirá reflexionar acerca del lazo entre inmigración, diversidad y derechos. Creemos que así podremos avanzar en e/ camino de un desafín mayar: prevenir y desarmar los discursas, las creencias y las prácticas xenófabas, y a la vez construir un concepto histórico de igualdad, capaz de contener y reconocer las diferencias (nacionales, étnicas, culturales, de génerם, etc.) sin esgrimirlas como razones "natura/es" para denegar u obstaculizar e/ acceso a derechos." ${ }^{\prime \prime 4}$

Esta definición política también se refuerza en términos pedagógicos pues se manifiesta la decisión de instalar esta problemática como tema en las escuelas a partir de la capacitación docente para trabajar los contenidos en el aula, su subtítulo es: "valija de materiales didácticos para trabajar en y desde la escuela". Para ello se añadió una propuesta de curso virtual ofrecido a través del Programa Nuestra Escuela y coorganizado por el Instituto Nacional de Formación Docente y el área de Inclusión Educativa de la Subsecretaría de Equidad y Calidad cuyos ejes fueron la diversidad y diferencia de la figura del "extranjero", las dinámicas inmigratorias a partir de información estadística aportada por los Censos, el encuadre normativo vigente en diferentes momentos históricos y el rol de la escuela.

Otro sitio de producción desde el Estado, el primero vinculado con esta temática es el Museo de la Inmigración, http://www.migraciones.gov.ar/accesible/indexP.php?museo, una web producida desde la Dirección Nacional de Migraciones, actual Ministerio del Interior, Obras Públicas y Vivienda. Desarrolla un tratamiento complejo y estructural del tema haciendo Clín \& Asociados. La historia enseñada. 20IG (22) ISSN 2362-3063 (digital), pp. 20-4D. UNL - UNLP 
referencia al contexto internacional y a la inmigración en el proyecto de la organización nacional así como al vínculo con el modelo agroexportador. También incluye el impacto social de la ola inmigratoria bajo el título "el nuevo rostro de la sociedad" e historiza las diversas leyes migratorias. Introduce muy buenas preguntas como

¿Par qué venían las inmigrantes? ¿Par qué millanes de persanas desde principias de/ sigla XIX emigraran masivamente, dejanda sus países de arigen para establecerse en tierras lejanas? ¿Cáma se cumbinarun los factares estructurales es decir, las condiciones de los países de arigen y de destina con las estrategias de los propias migrantes, es decir cóma decidían emigrar en función de sus proyectos, de la infarmación de la cual dispanían y de sus relaciones saciales primarias: amigos, parientes, paisanos? ¿Cuáles fueron los países desde los cuales partieron más emigrantes?", entre atras.

Si bien su desarrollo es básicamente textual, también genera uno visual a partir de la inclusión de una galería de fotos e infografías diversas. Resulta muy interesante cómo esta web se abre a otras, enlazando con otros museos de migración del mundo o espacios académicos dedicados a la temática, aunque perpetúa la lógica de autosuficiencia de la inmigración masiva europea descripta más arriba.

La entrada "Inmigración en Argentina" de Wikipedia, la quinta enciclopedia libre visitada en el mundo y escrita directamente por el público, periodiza -sin fundamentación alguna- la historia de la inmigración en un tiempo largo que se inicia con el poblamiento de América. Presenta diversas corrientes migratorias: colonización hispánica/ introducción forzada de esclavos africanos/ inmigración europea (1880-1950)/ inmigración a partir de 1950, sin distinguir tanto a la ocurrida mayoritariamente por razones políticas como a la inmigración latinoamericana. Reproduce la idea de una nación preexistente. Se presenta a la Argentina como un país de excepcional impacto inmigratorio. Esta entrada se basa en un lenguaje textual, apelando, en parte, a la cita de fuentes escritas, fotografías -no siempre contextualizadas- y estadísticas. El relato subraya en mayor medida el protagonismo de los pioneros, destacando el rol de padres fundadores como Aarón Castellanos en el marco del proyecto colonizador desplegado por Urquiza y en menor medida, las acciones del Estado Nacional o el papel de los inmigrantes organizados en el movimiento obrero, una vinculación clásica presente en casi todos materiales analizados que introducen la perspectiva del conflicto en el proceso migratorio transatlántico. En cuanto a la causalidad histórica, esta enciclopedia desarrolla una breve alusión a la Segunda Revolución Industrial y a la política de atracción de inmigrantes, particularmente a la Ley de Inmigración de Avellaneda. El tratamiento del tema parece fomentar el mito civilizatorio de la Argentina como un país blanco, conclusión que puede verse en el siguiente pasaje:

La inmigración de países vecinas, más a menas cuntinua a la largo de las siglas XIX y XX. Este tipa de inmigración que se remunta a las primeras civilizaciones agroalfareras aparecidas en territorio argentina, a diferencia de la inmigración eurapea, fue siempre considerada un problema por no estar inc/uida en la que debía ser fomentada en cumplimienta de la Canstitución. Wikipedia. [Consultado en marzo de 2016]

Una característica distintiva de este material digital, el más consultado por los escolares, es la extensa presentación de casos nacionales, organizada por continente y sector de continente, de españoles a bielorrusos, a partir de la cita de autores no académicos entre los cuáles prevalecen las historias de las colectividades.

Por último, analizamos una propuesta producida por un colectivo docente que busca compartir y socializar sus experiencias. En este caso, tomamos la Revista Sacapuntas ${ }^{15}$ (http://sacapuntasrevista.com.ar/la-gran-inmigracion/) y para una secuencia didáctica propuesta por la temática aquí abordada. Se trata del Cuadernillo La gran inmigración realizado por las docentes: Cecilia Chiappetta y Julieta Iurcovich en 2009 y que fue publicado en el número 6 de la 
revista en septiembre de 2010, en el marco de los festejos del Bicentenario de la Revolución de Mayo. El mismo propone un recorrido para trabajar la inmigración ultramarina de fines del siglo XIX y principios del XX en un aula de Ciencias Sociales en 6to grado de la escuela primaria. La propuesta se presenta a través de un $p d f$ de la versión impresa de la revista que no articula ni linkea a otros sitios. Su organización es lineal, se trata de la reproducción digital de una versión impresa que permite al docente imprimirlo y ponerlo a prueba en su aula, a modo de fotocopiable de otras revistas impresas. En su recorrido propone analizar y contextualizar la gran inmigración transatlántica de finales de siglo XIX y principios del XX. También, revisar las condiciones de expulsión y recepción, la idea de redes inmigratorias, los ámbitos de sociabilidad como el trabajo y la vivienda en las grandes ciudades y las problemáticas del movimiento obrero. Presenta una secuenciación de actividades con consignas de lectura y escritura con textos e imágenes. Propone un recorrido que responde tanto a los lineamientos curriculares vigentes en relación con la enseñanza de la Historia o Ciencias Sociales en las escuelas primarias como a las perspectivas históricas hoy validadas por el ámbito académico. A diferencia de la mayor parte de los materiales analizados, la idea de secuencia organiza esta propuesta a partir del planteo de una pregunta o problema que recorre las actividades: “ipor qué tantos europeos dejan sus países de origen y vienen a la Argentina en esta etapa?"16, y se retoma en el cierre (Siede, 2010). A través del qué hacer y cómo hacerlo, este material interpela las formas tradicionales de enseñar el problema de la inmigración, recuperando los recorridos académicos y pedagógicos que vienen buscando un lugar en las aulas desde el retorno de la democracia. Sin embargo, queda pendiente la vinculación de esta propuesta de enseñanza con el proceso de inmigración latinoamericana. Por lo menos en la web no hay números o propuestas de esta revista en los que se amplíen o articulen estas temáticas. Si bien no podemos generar las mismas afirmaciones vertidas para el caso de Valencia, deberíamos estar atentos a que éste no sea el único eje desde dónde trabajar la inmigración masiva.

Este recorrido permite advertir a los docentes y futuros docentes que una parte importante de los materiales digitales dedicados a las temática de la inmigración en Argentina se centran mayormente en el movimiento de población que arriba a la Argentina desde Europa entre los finales del siglo XIX y la primera mitad del XX, sin establecer relaciones y conexiones con otros procesos migratorios contemporáneos posteriores o actuales de la Argentina, reforzando así un tratamiento "autosuficiente" de la inmigración masiva, hipótesis ya subrayada por M. P. González para el caso de los textos escolares. Así, transmiten una imagen de nación que privilegia, por un lado, el desarrollo de la inmigración "europea, blanca y civilizada" y por otro, de una historia política y económica del contexto en que surgió que, sin embargo, en pocos casos incursiona en el tratamiento de la vida cotidiana o incluye cuestiones culturales o de género, a excepción de [Re] Pensar la Inmigración en Argentina. Las ideas de flujos y reflujos, condiciones de expulsión y de atracción se encuentran muy presente en todos los materiales analizados. En menor medida se muestran otros conceptos que habilitan análisis más complejos y centrados en las experiencias migratorias de los sujetos. Será necesario entonces prestar atención a un tratamiento del tema que visibilice las redes sociales y las estrategias migratorias que despliegan los hombres y mujeres en sus trayectorias personales definidas por las experiencias migrantes, las causas personales, familiares y microsociales, posibles de ser observadas en los análisis de caso. También los elementos que permiten identificar las recreaciones culturales y las identidades complementarias que la población inmigrante construye individual y colectivamente. Estos conceptos sustentados en desarrollos historiográficos actuales permiten abordar no solo las temáticas migratorias tradicionales en Argentina sino otros procesos migratorios contemporáneos en nuestro país, todas temáticas poco trabajadas en los materiales digitales analizados. Asimismo, en la mayor parte de los sitios prevalece el texto escrito. Podríamos decir que algunos de los

Clín \& Asociados. La historia enseñada. 20I6 (22) ISSN 2362-3063 (digital), pp. 20-4D. UNL - UNLP 
materiales analizados funcionan como "organizadores de archivos" (Andrade, 2014) apelando al uso del audiovisual para dar múltiples respuestas a estas temáticas, como es el caso de la valija que busca [Re] Pensar la Inmigración en Argentina. El uso de otro lenguaje es introducido por Valencia, historieta interactiva que privilegia el uso de la imagen, en ambos casos sus propuestas didácticas no incluyen pistas para el tratamiento de la especificidad de estos lenguajes.

\section{Conclusiones}

Sabemas ya que esculares y estudiantes suelen evitar consultar libros de texta y enciclapedias y van directamente a sacar naticias de Internet, tanto que desde hace tiempo sastengo que la nueva y fundamental asignatura que hay que enseñar en e/ calegin debería ser una técnica de selección de las noticias de la red; el prablema es que se trata de una asignatura difícil de enseñar. (Еса, 2006)

Los materiales escolares constituyen una ayuda necesaria y difícilmente prescindible que median la práctica cotidiana de los docentes y la producción de los estudiantes en el quehacer cotidiano del aula. Los materiales digitales no escapan a esta lógica y ocupan un lugar progresivamente más protagónico en las aulas de Historia.

En la mayor parte de los materiales escolares digitales analizados, tanto en aquellos producidos con ese fin como los que se convirtieron en tales producto del uso realizado por docentes y estudiantes, persiste la presentación de un conocimiento histórico acabado que asocia la identidad de la sociedad argentina con la inmigración transatlántica de fines del siglo XIX y principios del XX e incluye escasas referencias y articulaciones con los procesos migratorios de países limítrofes u otros orígenes. Detectar estas ausencias, entre otras, se convierte en un desafío a la hora de construir criterios de análisis para la selección y el uso de materiales digitales que circulen en la enseñanza de la historia, entre las aulas y las tareas escolares. Asociar los conocimientos historiográficos -sobre esto éste y otros temas- con materiales escolares de diferente naturaleza resulta importante para la formación inicial ${ }^{17}$ y continua de docentes, tanto para maestros en la enseñanza de las Ciencias Sociales en el nivel primario como para profesores en la enseñanza de la Historia en el nivel medio.

Si los estudiantes suelen evitar consultar libros de texto y enciclopedias y van directamente a buscar noticias de Internet, ¿para qué sirve un profesor de historia en la época de Internet?, nos preguntamos parafraseando a Eco. Esta pregunta nos vuelve a centrar en la cultura escolar en general y en las clases de historia en particular. Es que, ante la expansión de variados artefactos culturales como la radio, el cine, la televisión o Internet, un profesor de historia debe "formar", antes que informar, discutir los discursos aislados y de circulación casual y desordenada de los medios de comunicación y enseñar a buscar, filtrar, seleccionar o rechazar información histórica de Internet. Se trata de jerarquizar su lugar de mediador, entre libros, pantallas y lectores del profesor de historia, apelando a una enseñanza multisensorial de esta disciplina escolar.

Por ello esta investigación buscó proponer criterios que orienten a los docentes a una exploración de la disponibilidad de materiales digitales para armar su propia "biblioteca". Así, una vez seleccionadas las propuestas curriculares y definidas las cuestiones pedagógicas, los profesores estarán en condiciones de seleccionar aquellas propuestas que ofrecen estos materiales digitales y arribar a una práctica pedagógica eficaz que pone en juego las posibilidades y limitaciones de las tecnologías disponibles (Harris y Hofer, 2009). Para ello este trabajo ha generado nuevos interrogantes que abren caminos para la formación y la investigación sobre la enseñanza de esta dupla de formadoras de maestros y profesores de historia que queremos compartir: ¿cómo se usan los sitios de Internet en las clases de Historia? ¿Cuál es el peso del conocimiento historiográfico de maestros y profesores en el uso de esos materiales? ¿Cuál el 
aprovechamiento de los estudiantes? ¿Qué lugar tienen estos contenidos de las prácticas escolares en la formación docente inicial y continua?

\section{Listado de materiales digitales analizados}

Valencia, histarieta interactiva, http://histariavalencia.educ.ar/, consultada par última vez el 9 de marzo de 2016.

[Re] Pensar la Inmigración en Argentina http://valijainmigracion.educ.ar/, consultada por última vez el la de marzo de 20I6.

El Histariadar, http://www.elhistariadar.com.ar/ consultada por última vez el 19 de abril de 2016.

Histaria y antaganisma. Blag de/ histariadar Ezequie/ Adamavsky http://ezequieladamavsky.blagspat.com.ar/ consultado por última vez el 19 de abril de 2016.

Wikipedia (entrada "Inmigración en Argentina"), https://es.wikipedia.org/wiki/Wikipedia:Portada, consultada por última vez el lls de abril de 2016.

http://www.migraciones.gov.ar/accesible/indexP.php?musen consultado por última vez el I9 de abril de 2016.

Revista Sacapuntas, http://sacapuntasrevista.com.ar/la-gran-inmigracion/, consultada por última vez el l2 de marzo de 2016.

\section{Bibliografía}

Amézola, G. de; Carnevale, S. \& M. P. González (2009). Las futurus profesores y las lecturas de historia en las aulas de Argentina. Antíteses, 2(3), 93-113.

Andina, I.; Bello, C.; Belvedere, F.; Bula, V.; Chartier, M.; Iglesias, M. \& M. Rodríguez Bobadilla (2012). Las NTIC como herramienta en la enseñanza de la historia: Propuestas para abordar la Edad Media. Clía \& Asaciados. La historia enseñada, 16, 179-194.

Andrade, G. (2014). Materiales multimediales para la enseñanza de la Historia. En Zamboni, E.; Sabina Dias, F. \& S. Finacchio (arg.). Peabiru. Un camina, muitas trilhas. Ensina de História e Cultura Cantemparânea (I56-lö). Florianópolis: Letras Contemporâneas.

Andrade, G. et al (2012). Múltiples Voces para el Bicentenaria, una herramienta para pensar la enseñanza de la Histaria en el contexto del Modela I a I. En VIII Encantra Nacional Perspectivas da Ensina de História III Encantra Internacional de Ensina de História, Universidade Estadual de Lampinas.

Area Moreira, M. (2003). De los webs educativo al material didáctico web. Camunicación y Pedagagía, 180, 32-38.

Balsas, M. S. (2014). La imagen de la mujer inmigrante en los libros de texto. Canfiguraçães, 14, 151-175.

Bjerg, M. (2009). Historias de la inmigración en la Argentina. Buenos Aires: Edhasa.

Braslavsky, C. (1991). Los libros de texto en su contexta: Argentina 1975-1989. En Riekenberg, M. (comp.). Latinaamérica: enseñanza de la histaria, libros de textas y canciencia histórica (60-76). Buenos Aires: Alianza/FLACSD/Georg Eckert Instituts.

Brito, A. \& S. Finacchio (2009). (Enseñar a) leer y escribir, en presente y a futuro. Entrevista a Anne Marie Chartier. Propuesta Educativa, 32, 65-71.

Carvalho Koyama, A. (2013). Arquivos online: práticas de memória, de ensina de história e de educaçãa das sensibilidades. Campinas. (Tese de Doutorado. Universidade Estadual de Lampinas).

Cucuzza, R. (2009). Para todas los hombres del munda: el discursa historiográfica y política sabre la inmigración en los libros de lectura de la escuela primaria argentina (1853-1930). En Artieta, T. Los "atros" en los textas escalares. Canflictos en la canstrucción de imágenes de nación (35-65). Luján: UNLu.

Cuesta, V. \& E. Marchese (2013). Materiales virtuales: usos y posibilidades en la enseñanza de la historia reciente. Clía \& Asaciados. La histaria enseñada, 17, 267-282.

Devoto, F. (1992). Idea de nación, inmigración y cuestión social en la historiografía académica y en los libros de texto de Argentina. Estudios saciales, 3(1), 9-30.

Clín \& Asaciadas. La historia enseñada. 2016 (2Z) ISSN 2362-3063 (digital), pp. 20-4D. UNL - UNLP 
Doueihi, M. (2010). La gran conversión digital. Buenos Aires: FCE.

Eco, U. (2006). ¿¿De qué sirve el profesor? La Nación, Zl de mayo.

Eco, U. (2006). Los riesgos de wikipedia. La Nación, 29 de enero.

Escolano Benito, A. (2006). El libro escolar y la cultura de la educacín. La manualística, un campo en construcción. En Escolano Benita, A. (Ed.). Curriculum editado y saciedad de/ canocimienta. Texta, multimedialidad y cultura de la escuela (13-34). Valencia: Márgenes/ Tirant Lo Blanch.

Falaize, B. (2014). प ensino de temas controversos na escola francesa: as novas fundamentos da história escolar na França? Tempo e Argumenta, 6(II), 224-253.

Finocchio, S. (2011). La nueva trinidad pedagúgica en la enseñanza de las Ciencias Saciales. En 7ọ Congresa Internacional de Educación Santillana, Fundación Santillana, Asunción del Paraguay.

Finocchio, S. (2013). El papel de la educación en la invención de lo sacial (o de cómo la historia escolar transformó progresivamente lo sacial en la Argentina). Revista de Indias, LXXIII(257), 219-238.

Finocchio, S. (2013). Las invenciones de la dacencia en la Argentina (o de cómo la historia escolar transformó progresivamente a los enseñantes en sujetos resignados). Propuesta Educativa, 39, 41-53.

Finacchio, S. (2015). Conferencia inaugural. En IX Encantro Nacional Perspectivas do Ensino de História e a IV Encontro Internacional da Ensina de História, Universidade Federal de Minas Gerais, Belo Horizonte.

García Canclini, N. (2004). Diferentes, desiguales y descanectados. Mapas de la interculturalidad. Barcelona: Gedisa.

García Lanclini, N. (2007). Lectores, espectadores e internautas. Barcelona: Gedisa.

González, M. (2004). Formación de la ciudadanía e identidades: las cambios de la reforma educativa argentina: una mirada desde los libros de textos. En XV Simposio de Didáctica de las Liencias Sacia/es, AUPDCS, Alicante.

Grimson, A. (2015). Mitomanías argentinas. Buenos Aires: Siglo XXI.

Grimson, A. (2005). Relatos de la diferencia y la desigualdad: los balivianos en Buenos Aires. Buenos Aires: Eudeba.

Harris, J. y Hofer, M. (2009). Instructional planning activity types as vehicles for curriculum-based TPACK development. In Maddux, С. D. (Ed.). Research highlights in technology and teacher education (99-I08). Chesapeake: Society for Information Technology in Teacher Education (SITE).

Jenkins, H. (2008). Canvergence Culture. La cultura de la canvergencia de los medias de camunicación. Barcelona: Paidós.

Jahnsen, E. (1996). Textas escalares en e/calidascapio. Barcelona: Pomares-Corredor.

Koehler, M. \& P. Mishra (2009). What is technological pedagogical content knowledge? Contemporary /ssues in Technology and Teacher Education, Y(I), 60-70.

Main Fonseca, J. \& M. F. Silva Alves (2012). A História online: analizando sites de ensino de História no Brasil. En VIII Encuntro Nacional Perspectivas do ensino de Historia y III Encontro Internacional de Ensino de Historia, Universidade Estadual de Campinas.

Massone, M. (2Dil). Los jóvenes, la escuela y la transformación en la apropiación de los saberes. En Finacchio, S. \& N. Romero (Comp.). Saberes y prácticas escalares (153-173). Rosario: Homo Sapiens.

Massone, M. (2012). Enseñar a leer y escribir en Historia: los cambios en un contexto de transición cultural. Clía $\&$ Asaciados. La historia enseñada, I6, I52-167.

Massone, M. (2012). De los libros a Internet: cambios en las fuentes de creación del conocimiento en las clases de Historia. En Jornadas de Jóvenes Investigadores en Educación, FLACSQ, Buenos Aires.

Massone, M. (2013). La historia académica, la de divulgación y la escolar: algunas transfarmaciones en la era digital. En XIV Jarnadas Interescuelas/Departamentos de Historia, Universidad Nacional de Cuyo, Mendaza.

Merchán Iglesias, J. (2002). El usa de libros de texta en las clases de Historia. Gerónima de Lztariz, 17/18, 79-106. Neufeld, M.; Petrelli, L.; Sinisi, L. \& J. Thisted (2013). "Nuevos usas de la diversidad" en contextas barriales y escolares, en épocas de transformación sacial. En XIII Simpasio Interamericano de Investigación Etmográfica de la Educación. Mayorías, minarías y migraciones en perspectiva comparada. Universidad de California, Los Ángeles.

La inmigración a la Argentina en los nuevos materiales digitales - Massone y Andrade 
Pacceca, M. I. \& G. Averbuj (2014). Mirar y que te miren, pensar y que te piensen. Migraciones, diferencia y derechos en la escuela. Buenos Aires: Ministerio de Educación de la Nación.

Pimenta Arruda, E. \& L. Mara de Castro Simian (2009). Jagos digitais, juventude e as operą̧̃̃es da cognição histórica. En Guimaraes Fonseca (org.). Ensinar e aprender Historia. Formaçad, saberes a práticas educativas (231252). Campinas: Alinea.

Pimenta Arruda, E. (2011). Aprendizagens a jogos digitais. Campinas: Alínea.

Ramella, F. (1995). Por un usa fuerte del concepto red en los estudios migratorias. En Bjerg. M. \& H. Qtero (comp.). Inmigración y redes saciales en la Argentina Maderna (9- 21). Buenos Aires: CEMLA-IEHS.

Segal, A. (2012). Nuevas tecnologías y enseñanza de las ciencias sociales a partir de algunas ideas. En Goldin, D.; Kriscautzky. M. \& F. Perelman (coord.). Las TIL en la escuela, nuevas herramientas para viejos y nuevos problemas (337-364). México: Dcéano.

Siede, I. A. (2010). Preguntas y problemas en la enseñanza de las Ciencias Sociales. En Siede Isabelino A. (comp). Ciencias Saciales en la escuela (269-292). Buenos Aires: Aique.

Vigotsky, L. (1979). El desarrollo de los procesas psíquicas superiores. Barcelona: Crítica.

\section{Documentos curriculares}

Aisenberg, B.; Carnavale, V \& E. Larramendy, E. (200I). Una experiencia de Historia Oral en el aula: las migraciones internas en la Argentina a partir de 1930. ССВA. Secretaría de Educación. Recuperado de http://www.buenosaires.gob.ar/areas/educacion/_urricula/pdf/primaria/aportes/areas/saciales/historia__ral web.pdf

Diseña Curricular para el Primer Cicla de la Escuela Primaria, Primer Cicla y Segunda Ciclo, Secretaría de Educación del Gobierno de la Ciudad de Buenos Aires, 2004. Área Ciencias Saciales y Canacimiento del Mundo. Recuperado de http://www.buenosaires.gob.ar/areas/educacion/curricula/primaria.php

Diseño Curricular para la Educación Primaria, Primer Ciclo, Provincia de Buenos Aires, 2008. Recuperado de http://servicios2.abc.gov.ar/lainstitucion/organismos/consejogeneral/disenioscurriculares/documentasdescarga /primarialciclo.pdf

Diseño Curricular para la Educación Primaria, Segundo Ciclo, Pravincia de Buenas Aires, 2008. Recuperado de http://www.fmmeducacion.com.ar/Sisteduc/Buenosaires/Primaria/epbZ.pdf

Núcleos de Aprendizaje Prioritarios, Nivel Primario de ler cicla, Ministerio de Educación de la Nación, 2004. Recuperado de http://www.me.gov.ar/curriform/publica/nap/nap-egb-primario.pdf

Núcleas de Aprendizaje Prioritarios, Nivel Primario de 2do ciclo, Ministerio de Educación de la Nación, 2005. Recuperado de http://www.me.gov.ar/_curriform/publica/nap/nap_egb2.pdf

Núcleos de Aprendizajes Prioritarios Formación Ética y Ciudadana Campo de Formación General Ciclo Drientado Educación Secundaria, Ministerio de Educación de la Nación, 2012. Recuperado de http://www.me.gov.ar/consejo/resoluciones/res|2/180-12_44.pdf

Núcleos de Aprendizajes Prioritarios, Ciencias Saciales (Histaria - Geografía - Economía) Campo de Formación General Ciclo Drientado Educación Secundaria, Ministerio de Educación de la Nación, 20I2. Recuperado de http://www.me.gov.ar/consejo/resoluciones/res|2/180-12__l.pdf

Núcleos de Aprendizajes Prioritarios, Ciencias Saciales Ciclo Básico Educación Secundaria l0 y 20 / $2^{0}$ y $3^{0}$ Años, Ministerio de Educación de la Nación, 20ll. Recuperado de http://repositoriorecursosdownload.educ.ar/repasitorio/Dawnload/file?file_id=77fldcee-3723-4804-ac75-f6691589988248rec_id=110572

Profesorado de Educación Primaria Resolución № 6635 /L2, Gobierno de la Ciudad de Buenos Aires Ministerio de Educación Subsecretaría de Inclusión Escolar y Coordinación Pedagógica Dirección General de Planeamiento Educativo Direccí́n de Currícula y Enseñanza, 2009. Recuperado de http://www.buenosaires.gob.ar/areas/educacion/curricula/pdf/pep6635.pdf

Clío \& Asaciados. La historia enseñada. 20IG (22) ISSN 2362-3063 (digita)), pp. 20-4D. UNL - UNLP 
Serie Cuadernas para el Aula, Ciencias Saciales, 3er grado, Ministerio de Educación de la Nación, 2006. Recuperado de http://www.me.gov.ar/_curriform/nap/_ero_socia.pdf

Serie Cuadernos para el Aula, Ciencias Sociales, Gto grado, Ministerio de Educación de la Nación, 2008. Recuperado de http://www.me.gov.ar/curriform/nap/Зег___sacia.pdf

\footnotetext{
Notas

${ }^{1}$ Esta investigación está inscripta en el proyecto UBACyT 20020130100897BA2014-2016, "El orden del saber histórico en los materiales educativos digitales", dirigido por la Dra. Silvia Finocchio e inscripto en el Instituto de Historia Argentina y Americana "Dr. E. Ravignani”, Facultad de Filosofía y Letras - UBA.

${ }^{2}$ Es Profesora y Licenciada en Historia egresada de la Universidad de Buenos Aires y Especialista en Currículum y prácticas escolares y en Lectura, escritura y educación egresada de la Facultad Latinoamericana de Ciencias Sociales. Doctoranda con Orientación en Educación, Facultad de Filosofía y Letras, Universidad de Buenos Aires. Es Profesora Adjunta Regular de la cátedra "Didáctica especial y prácticas de la enseñanza de la Historia" en la carrera de Historia (FFyL, UBA), Profesora de Enseñanza de las Ciencias Sociales en el ENS $\mathrm{N}^{\mathrm{o}} 4$ y Capacitadora de docentes, directivos y bibliotecarios de escuela primaria del programa "CePA en la escuela" de la Escuela de Capacitación Docente de la Ciudad de Buenos Aires. Es autora de textos escolares, materiales de formación docente y artículos académicos publicados en diversos congresos y libros.

${ }^{3}$ Es Profesora de Historia egresada de la Universidad de Buenos Aires y Especialista en Educación y TIC por el INFOD - Ministerio de Educación de la Nación. Especialista en Ciencias Sociales con Orientación en Historia Social egresada de Universidad Nacional de Lujan y Maestranda en Ciencias Sociales por la misma universidad. Es autora de textos escolares y diferentes artículos publicados en revistas y congresos. Se desempeña como docente en diversos ámbitos de la Formación Docente inicial y continua (Cátedra Didáctica y Prácticas de la Enseñanza de la Historia de la Facultad de Filosofía y Letras -UBA, Cátedra de Enseñanza de las Ciencias Sociales de la Escuela Normal Superior $\mathrm{N}^{\circ}$ 4. Elaboración y dictado del Seminario Final de la Especialización en Ciencias Sociales para Primaria del INFOD). Formó parte de los equipos de capacitación de los programas Cepa en la escuela de la Escuela de Capacitación Docente de la Ciudad de Buenos Aires y Conectar - Igualdad del Ministerio de Educación de la Nación). Es vicerrectora de Asuntos Pedagógicos de la Escuela Técnica de la Universidad de Buenos Aires.

${ }^{4} \mathrm{Si}$ bien no contamos con datos actuales sobre porcentaje de uso de libros de texto hoy, resulta interesante considerar que, tal como lo propone Javier Merchán Iglesias: "el análisis del papel del libro de texto-o de otro tipo de materiales didácticos en el desarrollo de las clases de Historia puede hacerse considerando su potencialidad para actuar eficazmente no tanto -o no solo- en la trasmisión del conocimiento, sino -sobre todo- en la gestión de las interacciones que se dan en el interior de las aulas. De manera que, según esta perspectiva, la pertinencia y características de los libros de texto u otros materiales didácticos y, por tanto, su mayor o menor aceptación por parte de alumnos y profesores, así como su factura, vendrían dadas por su grado de coherencia y eficacia en relación con las lógicas dominantes en la práctica escolar" (2002:83).

${ }^{5}$ Definimos medio de comunicación siguiendo a Lisa Gutman citada por Jenkins: "Un modelo de medios que funciona en dos niveles: en el primero, un medio es una tecnología que posibilita la comunicación; en el segundo, un medio es un conjunto de 'protocolos' asociados o prácticas sociales y culturales que se han desarrollado en torno de dicha tecnología. Los sistemas de distribución son única y exclusivamente tecnologías; los medios son también sistemas culturales" (Jenkins, 2008:24).

${ }^{6}$ En los días que escribimos este artículo, estas políticas de inclusión digital están viviendo tiempos de incertidumbre, a partir de -entre otras medidas- los despidos masivos de trabajadores - entre otros, desarrolladores y educadores encargados de elaborar contenidos- del programa Conectar Igualdad. También se plantea su transferencia, sin recursos, a las provincias y/o su virtual cierre. Matías Ferrari "Políticas de Estado, fuera de servicio", Página 12, 25 de abril de 2016.

${ }^{7}$ Dentro de estas políticas públicas encontramos la Ley Nacional de Migraciones $N^{\circ} 25.871$ de 2003, el Programa Nacional de Normalización Documentaria Migratoria, denominado "Programa Patria Grande" (Decretos $\mathrm{N}^{\circ}$ 836/2004 y N$^{\circ}$ 578/2005) (regularización documental de las personas inmigrantes provenientes del MERCOSUR) o la acción del Instituto Nacional contra la Discriminación en relación con esta cuestión.

${ }^{8}$ Este relato naturalizado del "crisol de razas" transmitido por los mismos inmigrantes ultramarinos y sus descendientes y perpetuado en las historias orales de numerosas familias, en los manuales escolares, en las efemérides y en los medios de comunicación fue considerado emblema de la mezcla, la integración y la mejora racial, social y cultural. Seminario "Inmigración, diversidad y derechos humanos en la escuela. Una introducción a la temática”. Clase 1. Ministerio de Educación de la Nación. 2014-2015.

${ }^{9}$ Constitución de la Nación Argentina, 1853, 1949,1957 y 1994.
}

La inmigración a la Argentina en los nuevos materiales digitales - Massone y Andrade 
${ }^{10}$ Su reflejo en el sistema educativo puede ejemplificarse con el análisis del lugar de los migrantes en los libros de texto en Mouratian, P. (2014). "Análisis de libros escolares desde la perspectiva de los Derechos Humanos, por una educación inclusiva y no discriminatoria". CABA: Instituto Nacional contra la Discriminación, la Xenofobia y el Racismo (INADI), disponible en http://www.bnm.me.gov.ar/giga1/documentos/EL005389.pdf $\mathrm{O}$ en las recomendaciones de "Buenas prácticas en la comunicación pública" dirigido a periodistas y profesionales de la comunicación. Informe "Migrantes"; y dentro Programa Nacional de Formación Permanente "Nueva escuela", Ministerio de Educación de la Nación "Inmigración, diversidad y Derechos Humanos en la escuela".

${ }^{11}$ Con el objetivo de restituir el papel del Estado Nacional como garante de condiciones de igualdad educativa para la totalidad del sistema el Consejo Federal de Educación de la Nación resolvió (R. N ${ }^{\circ}$ 214/04) definir los Núcleos de Aprendizaje Prioritarios, "un conjunto de saberes centrales, relevantes y significativos, que incorporados como objetos de enseñanza, contribuyan a desarrollar, construir y ampliar las posibilidades cognitivas, expresivas y sociales que los niños ponen en juego y recrean cotidianamente en su encuentro con la cultura, enriqueciendo de ese modo la experiencia personal y social en sentido amplio", NAP de 1er ciclo de la escuela primaria, http://www.me.gov.ar/curriform/publica/nap/nap-egb-primario.pdf (p. 10).

${ }^{12}$ Se trata del historiador con mayor alcance de público de la Argentina. Una síntesis de su recorrido, pueden consultarse en http://fortunaweb.com.ar/2010-05-01-26750-felipe-pigna-el-historiador-que-tienen-marca-propia/

${ }^{13}$ Los minisitios o micro sitios lo componen una serie de materiales que forman parte de la propuesta de formación "Educ.ar en el aula" del portal Educ.ar. Se trata de portadas temáticas que desde materiales multimediales con diversos formatos se proponen incentivar la inclusión de herramientas y recursos TIC, en especial de los materiales producidos por el Ministerio de Educación de la Nación a través de Educ.ar y de los canales Encuentro y Pakapaka. [Re] Pensar la Inmigración en Argentina (2014), http://valijainmigracion.educ.ar/contenido/html/presentacion.html, consultado el 10 de marzo de 2016.

${ }^{15}$ Sacapuntas es una revista fundada por un grupo de maestras y maestros de CABA en marzo del 2008. La definen como "Una revista para volver la mirada sobre lo que hicimos y hacemos en la escuela, que no es poco. Unas palabras para ver cómo seguimos después de todo. Una herramienta abierta de y para nuestros colegas, un material que abra las puertas del aula para ver qué pasa".

${ }^{16}$ Revista Sacapuntas, 6, septiembre de 2010, disponible en http://sacapuntasrevista.com.ar/la-gran-inmigracion/, consultado el 12 de marzo de 2016.

${ }^{17}$ En relación con la formación inicial de docentes, compartimos la interesante pregunta que hacen G. de Amézola, S. Carnevale y M. P. González (2009) sobre qué leen y dan de leer los futuros profesores para la enseñanza de la historia en el nivel medio. El desafío entonces es formar a estos futuros profesores en el conocimiento de valiosos materiales escolares.

Clín \& Asociados. La historia enseñada. 20IG (22) ISSN 2362-3063 (digital), pp. 20-4D. UNL - UNLP 